\title{
Novos meios, novas práticas de ensino-apredizagem: proposta de produção colaborativa
} de um twiconto

\section{Resumo}

Tiago Ricciardi Correa Lopes

Universidade do Vale do Rio dos Sinos

tricciardi@ unisinos.br

Isa Mara da Rosa Alves

Universidade do Vale do Rio dos Sinos

ialves@unisinos.br

Este artigo apresenta uma proposta de produção colaborativa de um twitconto no Twitter com a finalidade de refletir sobre como os meios digitais podem contribuir para promover novas práticas de ensino-aprendizagem. $\mathrm{O}$ artigo apresenta hipertextualidade, emergência, convergência e conectividade como princípios que devem nortear o processo de elaboração de atividades pedagógicas que fazem uso de ferramentas e serviços oferecidos pelos meios digitais. Entendemos que quando aplicados em atividades de sala de aula, tais princípios contribuem para que ambientes de ensino-aprendizagem incorporem algumas qualidades semelhantes às que caracterizam comumente experiências de interação com meios digitais: imersão, engajamento por boas experiências, interatividade, colaboração, composição e superposição em uma mesma plataforma enunciativa.

\section{Palavras-chave}

ensino-aprendizagem; ambientes digitais; Twitter; colaboração

New media, new ways of teaching and learning: a proposal for collaborative production of a twiconto

\begin{abstract}
This paper presents a collaborative production of a twitconto using Twitter in order to think about how digital media can help us to promote new ways of teaching and learning. The article presents hypertextuality, emergence, convergence and connectivity principles that should guide the process of developing educational activities using tools and services offered by digital media. We understand that when these principles are applied to classroom activities, they contribute to enable the teaching-learning environments and to incorporate some qualities similar to those that commonly characterize experiences of interaction with digital media: immersion, engagement for good experiences, interactivity, collaboration, composition and overlapping on the same enunciative platform.
\end{abstract}

Key words

teaching-learning; digital environments; Twitter; collaboration

\section{Introdução}

Discute-se na literatura sobre o grau de diferenciação existente entre aqueles conhecidos como "nativos digitais" e os conhecidos como "imigrantes digitais" (ex.: Palfrey e Gasser, 2008; Thomas, 2011); no entanto, independente do grau de contraste entre as gerações, o que 
importa é que ambos estão expostos aos desafios gerados pelas transformações operadas pelos meios digitais sobre todas as áreas da cultura de nosso tempo.

Os alunos que recebemos nos diferentes níveis de ensino apresentam comportamento e ações próprios dessa cultura. Assim, buscar estratégias para incorporar esse modo de pensar e agir no processo de ensino-aprendizagem é indispensável para prepará-los a atuar no mundo fora das paredes da sala de aula de maneira ética, responsável, qualificada e, portanto, bemsucedida (ex.: Clark e Mayer, 2008; Thomas, 2011b).

Neste artigo, propomos refletir sobre como meios digitais podem contribuir para promover novas práticas de ensino-aprendizagem a partir da proposta de produção colaborativa de um twitconto no Twitter. Para tal, as próximas seções do artigo foram organizadas do seguinte modo: a segunda seção apresenta princípios para a formulação de atividades em ambientes digitais; a terceira seção apresenta uma proposta de escrita colaborativa no Twitter, abordando os temas microconto, microconto no twitter e contos colaborativos no Twitter; por fim, é apresentada a conclusão do trabalho.

\section{Princípios para a formulação de atividades em ambientes digitais}

Nesta seção, apresentamos os princípios de hipertextualidade, emergência, convergência e conectividade como aqueles que devem nortear o processo de elaboração de atividades de ensino-aprendizagem aportadas pelo uso de ferramentas e serviços oferecidos pelos meios digitais.

Quando nos referimos ao caráter hipertextual dos ambientes atravessados pelas lógicas das mídias digitais, evocamos menos as suas características técnicas e tecnológicas do que, por outro lado, as relações que se apresentam entre elementos quando dispostos em hipertextos. Portanto, interessam-nos particularmente os modelos mental e cognitivo implícitos no conceito de hipertexto, bem como o seu potencial de enunciação subjetiva expresso nas plataformas digitais, que podem servir de base para atividades de ensino-aprendizagem voltadas ao uso de mídias digitais. Para Xavier (2009, p. 89),

O hipertexto deve ser visto como o locus de processos virtuais que dá vida ao modo de enunciação digital. Este, por seu turno, é uma forma singular de enunciar, isto é, uma maneira própria de dispor, compor e superpor, entrelaçadamente, em uma mesma plataforma enunciativa, os recursos semióticos de natureza linguística e não-linguística - fato este que o torna distinto da escrita alfabética, ainda que dependente e profundamente nela enraizado.

Ambientes de ensino-aprendizagem, quando pensados sobre as lógicas da hipertextualidade, devem promover formas de enunciação marcadas pelo princípio de conexão entre elementos heterogêneos, de natureza linguística e não-linguística, de modo a criar plataformas de enunciação que se distanciem das formas lineares e sequenciais da escrita convencional. A hipertextualidade que se atualiza em ambientes desse tipo demanda, portanto, um tipo de habilidade dos indivíduos calcada sobretudo no descobrimento e na exploração dos seus conteúdos - que podem ser textos, imagens, sons etc. - criando redes de relações de sentidos muito variadas.

Outro princípio que devemos levar em conta quando pensamos em atividades em sala de aula que visem não somente ao uso de ferramentas e serviços ofertados pelos meios digitais, mas, sobretudo, a apropriação de dinâmicas de interação específicas destes ambientes, é o de emergência (Johnson, 2003). Conceito trabalhado em diversos campos - biologia, física, 
matemática, computação etc. -, a emergência define-se da seguinte maneira: em um dado sistema, a articulação de comportamentos simples nos baixos níveis podem gerar comportamentos complexos nos níveis mais altos do sistema. Ou seja, através de um movimento de baixo para cima (bottom up), um sistema se auto-organiza, sem a presença de regras e comandos estabelecidas de cima para baixo (top down) por uma liderança.

Seria este um padrão de comportamento encontrado em toda a natureza: algumas colônias de bactérias, que adotam distintas estratégias de comportamento dependendo das condições do meio-ambiente; as comunidades de formigas e cupins, nas quais seus membros realizam tarefas muito simples e especializadas, dando origem a estruturas altamente complexas, como os formigueiros e os cupinzeiros. É também um padrão que orienta o modo como ideias se formam no interior dos cérebros humanos, o modo como as cidades crescem e também o modo como operam os programas de inteligência artificial.

Johnson (2003) comenta que as pessoas tendem a reagir com estranhamento a esse tipo de governança sem liderança, pois estão acostumadas a pensar em termos de líder - governos, chefes, professores etc. $\mathrm{O}$ comportamento emergente mistura ordem e anarquia, há contribuições vindas de todos os lados e que apontam em diferentes direções, e é a partir das relações entre as diversas ações que começam a se formar padrões responsáveis por gerarem cond ições para que o sistema se auto-organize. Na web, a Wikipedia talvez seja o exemplo mais recorrente para entendermos como esse processo acontece. Nesse ambiente, a ação coletiva de grupos humanos, trabalhando juntos e de forma auto-organizante, atua no sentido de produção de novos saberes e informações a partir de meios digitais, sem um líder ou uma governança que não seja o próprio comportamento coletivo que regula o que pode e o que não pode ser publicado.

Para Jenkins (2008), a convergência apresenta-se antes como um fenômeno que acontece na esfera cultural da sociedade do que algo que decorre exclusivamente de transformações tecnológicas operadas nos meios de comunicação. De fato, a convergência tecnológica que presenciamos atualmente resulta no crescente acúmulo de funcionalidades assumidos pelos inúmeros aparelhos que nos acompanham em nosso dia-a-dia. No entanto, na medida em que estes aparelhos se transformam em suportes para a veiculação de conteúdos, observamos, em contrapartida, um esforço por parte das instituições midiáticas em produzir e direcionar seus produtos para todas as plataformas. Esse movimento é acompanhado de outro, que diz respeito às possibilidades de produção e distribuição de conteúdos que os consumidores passam a dispor com as tecnologias digitais.

Todo este movimento de convergência aponta, paradoxalmente, para uma dispersão e fragmentação generalizada da experiência de consumo midiático contemporânea. Cada vez mais os conteúdos encontram-se espalhados em diversas mídias e podem ser acessados em diferentes plataformas, a qualquer hora e em qualquer lugar. Portanto, o que muda radicalmente a partir dos processos de convergência é o perfil deste indivíduo que emerge como consumidor e produtor de produtos culturais e sobre o qual são demandadas novas habilidades e competências para lidar com os desafios apresentados nesse contexto.

Por fim, acreditamos que os princípios de hipertextualidade, emergência e convergência, que caracterizam os ambientes que se constituem a partir dos meios digitais de comunicação, operam pelo princípio geral de conectividade em múltiplas dimensões: técnica, estética, ética, discursiva, social, política, cultural, geográfica etc. A conectividade comparece, na cultura de nosso tempo, como uma espécie de grande demanda, que se traduz pela conexão generalizada das pessoas entre si, mas também das pessoas com os artefatos tecnológicos e com os espaços geográficos. 
Para Kilpp (2011), a conectividade que transparece como principal característica de nosso tempo, é resultante de um longo processo protagonizado pelos meios de comunicação. $\mathrm{O}$ "conectável", nos diz "que antes precisava estar próximo no tempo e no espaço, agora se encontra a um clic" (Kilpp, 2011, p. 43). Portanto, para Kilpp (2011), na medida em que se desmancham e se liquidificam as distâncias, o conectável emerge como a principal característica do nosso tempo.

Quando aplicados em atividades de sala de aula, esses princípios visam a, no limite, criar condições favoráveis para que ambientes de ensino-aprendizagem incorporem qualidades semelhantes às que caracterizam experiências de interação com meios digitais: imersão, agenciamento, interatividade e colaboração.

Em resumo, poderíamos falar no desejo de criação de ambientes de ensinoaprendizagem que sejam, ao mesmo tempo, imersivos (Murray, 2003), tal como se pudessem envolver seus participantes através de experiências próximas as que vivenciamos quando assistimos filmes ou quando jogamos jogos digitais; promovam a sensação de agência ou agenciamento, que se define pelo prazer resultante de respostas positivas às nossas ações quando em interação com um dado sistema (Murray, 2003); operem através de diversos tipos, níveis e graus de interatividade (Manovich, 2006); e que sejam, acima de tudo, colaborativos, instituindo a dimensão de conectividade e emergência que caracterizam os meios digitais.

\section{Uma proposta de escrita colaborativa no Twitter}

$\mathrm{Na}$ tentativa de propor uma atividade de ensino-aprendizagem em contexto digital que incorpore os princípios de hipertextualidade, emergência, convergência e conectividade, apresentaremos uma proposta de produção de um microconto colaborativo através do Twitter, um twitconto. Para tal, a seguir, discutiremos sobre o que é um microconto e sobre microcontos no Twitter para, então, na seção twitconto, apresentarmos a proposta de produção colaborativa.

\section{Microconto}

Não há uma definição formal e consensual para microconto. Em linhas gerais, o conceito pode ser definido como uma história contada com economia de palavras, conforme encontramos em uma citação atribuída ao professor Jarbas Novelino Barato, publicada no blog Microcontos do Carlos. Outros termos empregados em narrativas de formato curto que apresentam sentido muito próximo ao de microconto são: miniconto, nanoconto, minificção, microficção, microtexto etc. Ainda, os aforismos, que, segundo Rodrigues (2010) também se constituem em uma forma de literatura, mas não de narrativa, também se constituem como formato conciso que ganha especial destaque em tempos de economia de caracteres.

No site do projeto A casa de mil portas, um microconto se define da seguinte maneira:

Um microconto é, ao menos na nossa definição, uma história em prosa contada em cinquenta letras ou menos. Se parece pouco é porque é realmente pouco. Fazer um microconto é um desafio literário, uma tentativa extremamente econômica de contar ou sugerir uma história inteira. Um microconto exemplar, e possivelmente o mais famoso de todos, é do escritor guatemalteco Augusto Monterroso: "Quando acordou, o dinossauro ainda estava lá". 
Uma rápida pesquisa na $w e b$ revela diversos sites dedicados a esse formato narrativo, sendo possível encontrar, inclusive, um portal dedicado ao assunto. Ao navegarmos por alguns desses sites, percebemos que o limite de cinquenta caracteres, apontado na citação acima como condição para a criação de um microconto, não se constitui em regra geral: o site Cem toques cravados, como o próprio nome sugere, apresenta microcontos com exatamente cem caracteres; já no blog Minimínimos, o limite é o dobro, ou seja, até duzentos caracteres; o blog Microcontos da Zezé é limitado a cento e cinquenta caracteres, parecendo ser este um dos formatos mais recorrentes, juntamente ao de cento e quarenta caracteres, que, conforme já vimos, é o limite estabelecido tanto pelo Twitter quanto pelos serviços de SMS, o que provavelmente contribui para a popularização de microcontos com essa extensão.

Não importando tanto o nome que se dê ou o limite de caracteres para fazê-lo, o que se destaca nesses formatos narrativos é a característica de desafio em se conseguir contar uma história com tão pouco espaço.

\section{Microcontos no Twitter}

Não chegam a ser novidade as práticas de uso do Twitter para geração de microcontos. No Brasil, a prática de produção de microcontos no Twitter encontra-se de tal forma difundida que concursos sobre o tema já foram realizados. Apenas para ficarmos nos mais importantes, o próprio site do Twitter promoveu, em abril de 2008, um concurso e, mais tarde, em 2010, a Academia Brasileira de Letras promoveu outro, cuja vencedora foi esta história, publicada no blog Todaprosa, do colunista da revista Veja, Sérgio Rodrigues (2010): "Toda terça ia ao dentista e voltava ensolarada. Contaram ao marido sem a menor anestesia. Foi achada numa quarta, sumariamente anoitecida".

Uma pesquisa no campo de busca do site do Twitter apresenta vários usuários que se dedicam à produção de microcontos. O escritor Carlos Seabra, autor do blog Microcontos do Carlos, possui no Twitter o nome de usuário@microcontos. Observando sua página de perfil no site, encontramos este microconto: "A mulher-gorila fugiu com os irmãos siameses. Denunciados pelo dono do circo, eles foram presos por bestialismo e ela por bigamia".

Outros dois perfis de usuários dedicados exclusivamente à produção de microcontos são @miniconto e @contoscurtos. Vejamos dois microcontos encontrados na página de (a)contoscurtos: "Após 20 anos juntos, o fim do relacionamento foi um salto no escuro que os afetou de forma diferente: ela começou a voar; ele começou a cair." "Ele comprou o celular ansiando pela liberdade do movimento. Mas logo percebeu que, acessível em qualquer lugar, ficara realmente preso".

Poderíamos questionar se o conceito de "conto" se aplica efetivamente aos exemplos apresentados. No entanto, ainda que possa resultar interessante uma discussão acerca dos efeitos que incorrem sobre a especificidade dos gêneros literários ao serem transpostos para o formato de cento e quarenta caracteres, não teríamos condições de desenvolvê-la no espaço desse texto, nem tampouco é este o nosso propósito maior.

Por outro lado, caberia realizarmos um breve comentário acerca do potencial apresentado pelo formato de microconto para se trabalhar a função poética da linguagem, em combinações sonoras e rítmicas que produzem deslocamentos e intercâmbios de imagens e ideias. Em virtude do formato comprimido, o recurso poético aparece como tática para "abrir" o texto a interpretações variadas, convidando o leitor a participar de um jogo de interpretação que ocorre rapidamente e, por vezes, de forma aguda. Um mecanismo semelhante ao que provoca o humor quando ouvimos uma piada. Assim como na piada, o efeito de sentido provocado pelo texto 
sobre o leitor só se completa ao final da narração, normalmente, através de um desfecho imprevisto, seja por contrariar uma expectativa ou, como é possível observarmos em alguns dos microcontos supracitados, por brincar com as múltiplas possibilidades de sentido das palavras.

\section{Contos colaborativos no Twitter}

Uma outra prática, não tão difundida quanto a produção de microcontos, é a produção de contos colaborativos no Twitter. O caso mais conhecido desse tipo de iniciativa é o projeto Tim Burton's Cadavre Exquis, promovido pelo TIFF Bell Lightbox e ocorrido entre novembro e dezembro de 2010 como parte das atividades promocionais de uma exposição sobre a vida e a obra de Tim Burton.

O objetivo era a criação de uma história coletiva protagonizada pelo personagem Stainboy, do cineasta Tim Burton. A história começava com um primeiro tweet, de Tim Burton, descrevendo uma situação com o personagem Stainboy, que iniciava assim: "Stainboy, com toda a sua perspicácia, foi chamado para investigar uma gosma brilhante no chão da galeria..." (Vitulli, 2011). No próprio site do projeto, aqueles que desejassem continuar a história, poderiam tuitar através de um campo para inserção de texto conectado ao Twitter. A cada dia eram escolhidos os melhores tweets para continuar a história, assim, sempre que alguém se dispusesse a contribuir, deveria acessar o site e acompanhar a narrativa até o último tweet escolhido, sendo este o ponto a partir do qual a história deveria avançar.

Importante destacar que o termo cadavre exquis (em português, cadáver esquisito), que aparece no nome do projeto, resgata uma antiga prática de criação artística coletiva inventada pelos surrealistas. O cadáver esquisito deve ser "jogado" em grupo e pode servir tanto para a criação de desenhos quanto de textos colaborativos. Para jogar, dobra-se uma folha de papel em seções regulares, em número igual ao de participantes. Se o objetivo for criar uma história, o primeiro participante escreve na primeira seção o trecho inicial e passa a folha ao segundo participante. Este, então, escreve novo trecho, continuando a história iniciada pelo primeiro. Em seguida, o segundo participante dobra, de modo a esconder a seção da folha com o trecho inicial escrito pelo primeiro participante, e passa para o terceiro, que conseguirá ver a continuação, mas não o início da história. Repete-se o processo: escreve-se a continuação baseada somente na última intervenção para que o participante seguinte possa continuar. Ao final, desdobra-se a folha e lê-se o resultado, quase sempre surpreendente devido às conexões inimagináveis que se estabelecem ao longo do processo.

Poderíamos considerar que projetos como o Tim Burton's Cadavre Exquis, ainda que se façam uso de uma dinâmica de participação coletiva para a escrita de uma história, tendem a ignorar o princípio de permitir o "descontrole" do curso narrativo, o que talvez constitua a principal característica dos textos escritos através da prática de "cadavre exquis" pelos surrealistas.

No entanto, e por outro lado, tendem a evidenciar algumas das caraterísticas presentes nos usos de algumas ferramentas e serviços disponibilizados sobretudo na web, que trazem à tona o potencial de apropriação desses recursos para a produção de atividades em sala de aula conectadas aos princípios dos ambientes digitais anteriormente descritos.

Portanto, relataremos e analisaremos, em seguida, uma proposta de produção colaborativa através do Twitter para alunos de graduação, a criação de um conto colaborativo, ou melhor, de um twitconto.

\section{Twitconto}

V. 9 № 2, dezembro, 2011 
$\mathrm{Na}$ tentativa de exemplificar a incorporação de dinâmicas de ensino-aprendizagem cujos pressupostos instauram condições favoráveis à emergência de ambientes atravessados pelas lógicas subjacentes aos meios de comunicação digitais - em especial, a hipertextualidade, a emergência, a convergência e a conectividade -, nesta seção, apresentamos uma atividade de produção de uma narrativa colaborativa através do Twitter com alunos de graduação.

O Twitter é um dos dispositivos digitais que nasce em meio à popularização dos pressupostos trazidos pelo conceito de Web 2.0 (O'Reilly, 2005) e é frequentemente usado pela geração digital. O Twitter reúne elementos das redes sociais, dos blogs e das mensagens via mensageiros instantâneos ou SMS - Short Message System (Orihuela, 2007). Dos blogs, ele herda as propriedades de atualização frequente, geralmente disponibilizadas em ordem cronológica inversa, a possibilidade de comentar determinada postagem e a possibilidade de disponibilizar uma lista de blogs (blogroll). Das redes sociais, o Twitter herda a possibilidade de criação de um perfil, de seleção de contatos para seguir, interagindo através dos posts (visíveis publicamente, ou somente pelos seguidores, conforme configuração) ou de mensagens privadas. Dos mensageiros instantâneos (Messenger, Google Talk, SMS via celular), o Twitter herda a característica de oferecer uma forma de comunicação curta (140 caracteres, como o SMS), com a possibilidade de ser direcionada a uma única pessoa ou a várias.

Desde sua criação em 2006, as respostas disponibilizadas em tempo real e sem filtros - os tweets - à pergunta What are you doing? (em português, o que você está fazendo?) tem variado bastante. Assim como os blogs, o Twitter amadureceu e hoje é utilizado não só para banalidades, mas também para noticiar e formar opiniões. A decisão sobre a presidência da república em diversos países, por exemplo, é também influenciada pelas interações que ali ocorrem.

A proposta de produção colaborativa aqui relatada utiliza o microblog Twitter como ferramenta de criação coletiva de texto. Essa atividade foi elaborada para ser usada como exercício de redação de narrativa interativa e foi batizada de twitconto.

Após trabalhar com as características dos gêneros conto e microconto, a atividade com o Twitter é iniciada envolvendo 5 fases: (1) produção do início do conto; (2) escolha do melhor início de conto; (3) escolha da hashtag (sinal \# seguido da expressão desejada); (4) produção do twitconto; (5) discussão. As etapas (1-3 e 5) ocorrem em sala de aula com todos os alunos presentes. A etapa (3) acontece a distância ao longo da semana, sendo importante estabelecer uma sequência para cada aluno postar sua parte da história e prazos máximos para que cada aluno faça a sua postagem de modo que na semana seguinte o conto esteja concluído.

$\mathrm{Na}$ primeira etapa, todos os alunos criam um início de uma história (limitada em 140 caracteres). A segunda etapa é para a votação e escolha do texto que será usado como início da história (é o primeiro capítulo, ou twitcapítulo). A terceita etapa é dedicada à escolha da hashtag que deve ser utilizada por todos ao fazer suas postagens. Um exemplo é a hashtag \#twitconto. A definição de uma hashtag, que funciona no Twitter como um link, possibilita facilmente o rastreamento dos twitcapitulos.

Escolhida a hashtag, inicia-se a terceira etapa, que ocorre a distância, dedicada à cons trução colaborativa do twitconto pelos alunos ao longo da semana. O conteúdo da postagem pode ser acompanhado por imagens ou vídeos, seguindo uma lógica convergente de produção de conteúdo. No momento de encontro presencial seguinte com a turma, após todos os alunos terem postado continuações da história, passa-se à etapa final: discute-se o que foi produzido e, acima de tudo, como foi o processo de elaboração conjunta da história.

Nessa fase, várias questões são levantadas: como ocorre o processo de retextualização ou 
recriação de um gênero textual tradicional (o conto) para uma mídia social online como o Twitter, que limita as intervenções em 140 caracteres? Como fica a questão da participação coletiva? E o que dizer sobre a possibilidade de integrar texto, imagem e vídeo?

Sobre a prática relatada, alguns aspectos são particularmente interessantes para a discussão que empreendemos neste artigo. O primeiro é o uso do Twitter para a produção de texto literário, quando, na verdade, não se trata de um serviço voltado a esta finalidade. Nesse sentido, apropriar-se do Twitter para criação de textos literários coletivos é pensar sob a lógica do remix e da conectividade, que são duas das características que marcam os processos nas mídias digitais. Portanto, trata-se de "pensar digitalmente" antes de pensar o simples "uso" de ferramentas digitais.

O segundo aspecto é a própria lógica da negociação que se estabelece na medida em que a "autoria" do texto é colocada em xeque quando todos participam da construção da mesma história: é preciso ser compreensivo, ser flexível e ter espírito de grupo para não haver frustração com possíveis caminhos que a história tome e que inevitavelmente acabam por desagradar alguns.

Por não haver um controle de censura sobre o conteúdo postado por cada aluno, corre-se o risco de haver intervenções que provoquem rupturas com a linha narrativa estabelecida. Dessa maneira, cabe ao aluno que se vê diante do momento em que deve criar um twitcapítulo cooperar ou não para manter uma dada tendência do texto. Evidentemente, nem todos cooperam, há aqueles que deliberadamente buscam uma ruptura, ou "sabotagem", ou, conforme uma gíria recorrente entre os membros da geração digital, visam "trollar" a atividade. Quando isso acontece, cabe ao aluno seguinte na sequência dos participantes, tentar retomar o estado anterior da narrativa, ou, noutro sentido, contribuir para intensificar o desvio. Podemos dizer que é a cultura emergente que se manifesta aí, tendo em vista que há um movimento botton up de construção de narrativa. O conto como um todo vai sendo organizado (e se autoorganizando) a partir de cada postagem individual.

Com a ausência de censura, é mais fácil de chegarmos próximos a um resultado final semelhante ao que os surrealistas buscavam nas práticas de "cadavre exquis". Por outro lado, pode-se buscar formas de sofisticação, colocando-se regras de participação e sanções para aqueles que as infringirem. Uma possibilidade que se apresenta nesse sentido e que toma como referência o modelo apresentado no projeto Tim Burton's cadavre exquis é a de estabelecer um tipo de dinâmica no qual todos os alunos devem, por exemplo, propor continuações para todos os capítulos, sendo escolhido, por meio de votação ou outro meio, aquele que permanecerá como a continuação "oficial".

\section{Conclusão}

Este artigo desenvolveu-se na tentativa de pontuar princípios para que sejam incorporadas dinâmicas de ensino-aprendizagem cujos pressupostos instauram condições favoráveis para a emergência de ambientes atravessados pelas lógicas subjacentes aos meios de comunicação digitais. Quando aplicados em experiências de sala de aula, os princípios da conectividade, hipertextualidade, emergência e convergência visam a viabilizar ambientes de ensinoaprendizagem apresentem algumas características que representam os ambientes digitais: imersão, engajamento por boas experiências, interatividade, colaboração, composição e superposição em uma mesma plataforma enunciativa.

Para concluir, sugerimos que o dispositivo de educação contemporâneo beneficia-se de condições estratégicas favoráveis para a penetração dos meios de comunicação digitais que 
estão presentes em todos os momentos da vida cotidiana e da consequente naturalização das suas lógicas nas práticas de ensino-aprendizagem. Atividades de criação de narrativas literárias colaborativas surgem principalmente em decorrência desse cenário e possibilitam experimentos atravessados por novos paradigmas vinculados à cultura digital, tal como procuramos demonstrar.

Acreditamos que a educação contemporânea precisa estabelecer suas dimensões de interfaceamento com a cultura de produção e consumo de informação aportada pelas mídias digitais. Toda a conectividade e o modo de pensar e agir que ela traz consigo precisam ser aproveitados para potencializar o processo de ensino-aprendizagem. Por fim, enfatizamos que "pensar digitalmente" as práticas pedagógicas é um procedimento produtivo e consiste em apreender as lógicas do digital e aplicá-las a diversos contextos, sejam ambientes onde prevaleçam meios digitais ou analógicos, sejam on ou offlines.

\section{Referências bibliográficas}

CLARK, R. C. e MAYER, R. E. E-learning and the science of instruction: proven guidelines for consumers and designers of multimedia learning. Sand Francisco: Pfeiffer, 2ed, 2008

JENKINS, H. Cultura da Convergência. Aleph, 2008.

JOHNSON, S. Emergência: a vida integrada de formigas, cérebros, cidades e softwares. Tradução: Maria Carmelita Pádua Dias. Rio de Janeiro: Jorge Zahar Editor, 2003.

KILPP, S. Imagens conectivas da cultura. Revista FAMECOS. v.17.n.3. set/dez 2011. p. 181189.MANOVICH, L. EI lenguaje de los nuevos medios de comunicación. Paidós, 2006.

MURRAY, J. Hamlet no Holodeck: o futuro da narrativa no ciberespaço. Tradução de Elissa Khoury Daher e Marcelo Fernandez Cuzziol. São Paulo: Itaú Cultural, Unesp, 2003.

O'REILLY, T. What is web 2.0. Designing patterns and business models for the next generation of software. 2005. Disponível em: http://oreilly.com/web2/archive/what-is-web20.html, Acesso em: 22 de julho de 2011.

ORIHUELA, J. L. Twitter y el boom del microblogging. Educ.ar: Educación y TIC. In. Perspectivas del Mundo de la Comunicación. N. 43, nov/dez 2007, p. 2-3.

PALFREY, J.; GASSER, U. Born digital: understanding the first generation of digital natives. New York: Basic Books, 2008.

RODRIGUES, Sergio. Concurso Todaprosa de microcontos para o Twitter. 2010. Disponível em: <http://veja.abril.com.br/blog/todoprosa/vida-literaria/concurso-todoprosa-de-microcontospara-twitter/> Acessado em: 20 de maio de 2011.

THOMAS, M. (ed). Desconstructing Digital Natives. New York: Routledge, 2011.

XAVIER, A. C. A e ra do hipertexto: linguagem e tecnologia. Recife: Ed. Universidtária da 
UFPE, 2009. 